\title{
Diagnosis and management of breast lymphoma: a single-institution retrospective analysis
}

\author{
Armando Orlandi ${ }^{1}$, Alejandro Martin Sanchez ${ }^{2}$, Maria Alessandra Calegari ${ }^{1}$, Sabatino D'Archi ${ }^{2}$, Angela \\ Santoro $^{3}$, Alba Di Leone ${ }^{2}$, Antonio Mulè ${ }^{3}$, Vincenzo Arena ${ }^{3}$, Riccardo Masetti ${ }^{2}$, Carlo Barone ${ }^{1}$, Gianluca \\ Franceschini $^{2}$
}

${ }^{1}$ Division of Medical Oncology, ${ }^{2}$ Division of Senology, ${ }^{3}$ Department of Laboratory and Diagnostic Medicine, Catholic University of the Sacred Heart, Rome, Italy

Contributions: (I) Conception and design: A Orlandi, AM Sanchez, MA Calegari, A Mulè, G Franceschini, R Masetti, C Barone; (II) Administrative support: AM Sanchez; (III) Provision of study materials or patients: A Orlandi, AM Sanchez, MA Calegari, S D’Archi, A Santoro, V Arena; (IV) Collection and assembly of data: MA Calegari, AM Sanchez, S D’Archi, A Santoro, V Arena; (V) Data analysis and interpretation: A Orlandi, MA Calegari; (VI) Manuscript writing: All authors; (VII) Final approval of manuscript: All authors.

Correspondence to: Armando Orlandi. Division of Medical Oncology, Catholic University of the Sacred Heart, 00168, Rome, Italy.

Email: armando.orlandi@policlinicogemelli.it.

Background: Breast lymphoma (BL) is a rare entity. Although mimicking clinical presentation and radiological features of epithelial breast malignancies, prognosis and treatment management are different. Here we report our single institution experience in such population.

Methods: The database of our pathology institute was retrospectively searched for breast neoplasms coded as lymphoma from January 2000 to January 2017. The assessed data were: gender, age at diagnosis, laterality, stage (primary or secondary), histopathological diagnosis and grading (high $v$ s. low) treatment, recurrence and survival status. Progression-free survival (PFS), overall survival (OS) and 5-year recurrence rate were estimated. An exploratory analysis comparing survival (PFS, OS and 5-year recurrence rate) between highand low-grade histotypes and primary and secondary stages was performed.

Results: Fifteen patients were included in the analysis. All patients were affected by B-cell type lymphomas; the most frequent subtype was diffuse large B-cell lymphoma (DLBCL). Patients affected by high-grade lymphomas were treated with polychemotherapy followed in about half of cases by consolidative ipsilateral breast radiotherapy. Patients affected by low-grade lymphomas were treated with local treatment only (surgical resection +/- radiotherapy). No patient received radical surgery or axillary dissection. At a median follow up of 9 years, four patients had relapsed (all affected by high-grade lymphomas) with central nervous system (CNS) involved in half cases. Both median PFS and OS were not reached, but a slight trend toward a better survival was noticed in favor of primary breast lymphoma (PBL), while a clearer survival benefit was observed in the low-grade cohort. The estimated 5 -year survival rate was $77 \%$ within the whole population, $78 \%$ vs. $66 \%$ for primary vs. secondary and $100 \%$ vs. $66 \%$ for low-grade vs. high-grade BL.

Conclusions: Our data concerning clinical and pathological features are consistent with those previously reported. Management of disease was based on histology. Although being a rare disease it is mandatory to take it into account for differential diagnosis since treatment and prognosis differs widely from primary breast malignancies.

Keywords: Primary breast lymphoma (PBL); secondary breast lymphoma (SBL); high grade lymphoma; low grade lymphoma

Submitted Jul 25, 2017. Accepted for publication Aug 31, 2017.

doi: $10.21037 /$ tcr.2017.11.10

View this article at: http://dx.doi.org/10.21037/tcr.2017.11.10 


\section{Introduction}

Breast lymphoma (BL) is a rare form of extranodal lymphoma (ENL) (1). It accounts for 1.7-2.2\% of ENL (2) and represents $0.4-0.5 \%$ of breast malignancies (3-7), while being overall the most common extramammary cancer involving the breast $(8,9)$. BLs have been categorized into primary breast lymphoma $(\mathrm{PBL})$ and secondary breast lymphoma (SBL) types (10). BLs are classified as PBLs according to the criteria described by Wiseman and Liao (11) and modified by Hugh et al. (12), which include: presence of closely associated mammary tissue and lymphomatous infiltrate in an adequate specimen for pathologic evaluation, no previous diagnosis of extramammary lymphoma and lack of synchronous widespread disease other than simultaneous ipsilateral axillary nodes. SBLs are defined by the presence of secondary involvement of breast tissue by a concurrent or previous systemic lymphoma. SBLs are more frequent than PBLs.

Clinical presentation and radiological findings of BLs are non-specific and mimic those of primary breast cancer (BC) $(13,14)$. Therefore, differential diagnosis relies on pathological examination and biopsy is mandatory (15). Staging is based on ${ }^{18} \mathrm{~F}$-FDG CT-PET and brain MRI in case of neurological symptoms (16). PBLs behave similarly to nodal lymphomas (NLs) harboring the same stage and histology, notably in the rituximab era no significant difference in clinical outcomes is detected between PBL and NL (17). Instead, outcomes of PBL are worse compared to those of epithelial BC. Indeed, for PBL the 5-year survival rate and recurrence rate are $40-80 \%$ and $15 \%$ respectively, whilst for $\mathrm{BC}$ the survival rate and recurrence rate at 10 years are $89 \%$ and $12 \%$ respectively (18). Moreover, treatment of BL differs much form that of BC. Thus, it is crucial to secure an early and accurate histological diagnosis in order to select the best management and avoid mistreatment, including potentially harmful surgeries.

We conducted a retrospective observational study with the aim to report prevalence, features and management of BLs at our institution.

\section{Methods}

This is a retrospective observational study. The pathology database of our institute (Fondazione Policlinico Universitario Agostino Gemelli) was used to identify all breast neoplasms coded as lymphoma diagnosed from January 2000 to January 2017. Both primary and secondary
BL were included. Each case was retrospectively reviewed by an experienced pathologist with the aim of confirming whether the neoplasm was correctly coded. Baseline demographic information and clinical follow-up data were collected from review of electronic medical charts; pathological features were retrieved from histological reports. The assessed data are the following: gender, age at diagnosis, laterality, stage (primary or secondary), histopathological diagnosis and grading (high vs. low) according to WHO nomenclature (19), treatment, recurrence and survival status. Progression-free survival (PFS) was defined as the time from the start of the treatment to the date of the first documented progression disease or death due to any cause, whichever occurred first. Overall survival (OS), was defined as the time from the start of the treatment to the date of death due to disease, or censored at the date of last follow-up for alive patients. Recurrence rate at 5-year was calculated. The KaplanMeier method was used to estimate OS, PFS and 5-year recurrence rate. An exploratory analysis comparing survival (PFS, OS and 5-year recurrence rate) between high- and low-grade histotypes and primary and secondary stages was performed. Data were analyzed using IBM SPSS Statistics version 22 software.

\section{Statement of ethics approval}

This is a retrospective and observational study and no approval by the Ethics Committee is required. Each patient was treated as well as in clinical practice. All patients at the time of surgery and the onset of chemotherapy have signed an informed consent, authorizing the use of their anonymized data for scientific purposes.

\section{Results}

Within the study period, 15 samples were coded as lymphomas and were included in the analysis. Demographics and baseline characteristics of study population are summarized in Table 1. Females were affected more frequently compared with males, 13 (87\%) vs. $2(13 \%)$ respectively. The median age at diagnosis was 64 years (range, 10-82 years). All patients presented with a solitary mass, occurring in 7 cases within the left breast (47\%) and in 8 cases (53\%) within the right breast; no case of bilateral involvement was reported. According to the criteria by Wiseman and Liao, 10 cases were classified as PBL (67\%) and 5 cases as SBL (33\%). All neoplasms were 
Table 1 Patients' characteristics

\begin{tabular}{|c|c|}
\hline Characteristics & Data \\
\hline \multicolumn{2}{|l|}{ Age, years } \\
\hline Median & 64 \\
\hline Range & $10-82$ \\
\hline \multicolumn{2}{|l|}{ Gender, n [\%] } \\
\hline Male & $2[13]$ \\
\hline Female & $13[87]$ \\
\hline \multicolumn{2}{|l|}{ Primary side, n [\%] } \\
\hline Left breast & $7[47]$ \\
\hline Right breast & 8 [53] \\
\hline \multicolumn{2}{|l|}{ Type, n [\%] } \\
\hline PBL & 10 [67] \\
\hline SBL & 5 [33] \\
\hline \multicolumn{2}{|l|}{ Histology, n [\%] } \\
\hline B-cell lymphoma & $15[100]^{\S}$ \\
\hline DLBCL & $8[53]^{\S}$ \\
\hline MZL & $2[13]^{*}$ \\
\hline Plasmablastic & $2[13]^{\S}$ \\
\hline Follicular & $1[7]^{\star}$ \\
\hline Burkitt & $1[7]^{\S}$ \\
\hline Linfoblastic & $1[7]^{\S}$ \\
\hline
\end{tabular}

§, high-grade lymphoma; *, low-grade lymphoma. PBL, primary breast lymphoma; SBL, secondary breast lymphoma; DLBCL, diffuse large B-cell lymphoma; MZL, marginal zone lymphoma.

B-cell type lymphomas. Diffuse large B-cell lymphoma (DLBCL) was the most frequent type with 8 cases (53\%); of those 6 cases were classified as PBL and 2 cases as SBL. Rarer histological types were the following: marginal zone lymphoma (2 cases, $13 \%$, classified as PBL), plasmablastic lymphoma (2 cases, $13 \%$, one classified as PBL and one as SBL), follicular lymphoma (1 case, 7\%, classified as PBL), Burkitt lymphoma (1 case, 7\%, classified as SBL) and B-cell lymphoblastic lymphoma (1 case, 7\%, classified as SBL). Given such classification, only 3 cases ( 2 marginal zone lymphomas and 1 follicular lymphoma) accounting for $20 \%$ were low-grade BL (Figure 1), the remaining 12 samples were high-grade BL (Figure 2).

Diagnosis was obtained in each case with a sequence of fine-needle aspiration, which posed the cytological suspect of lymphoproliferative disease, followed by excisional biopsy, which allowed a histological confirmation. Once achieved a clear histopathological classification, all patient underwent computed tomography scan of the chest, abdomen and pelvis (more recently ${ }^{18} \mathrm{~F}-\mathrm{FDG}$ CT-PET scan) and bone marrow biopsy, in order to allow a correct staging. Treatment was established according to both staging and histology. Patients affected by DLBCL received anthracycline-based chemotherapy and rituximab followed in half of cases by consolidative ipsilateral breast radiotherapy. The chemotherapy regimen included cyclophosphamide, doxorubicin, vincristine and prednisone (CHOP), combined with rituximab. Patients affected by plasmablastic lymphomas, Burkitt lymphoma and B-cell lymphoblastic lymphoma were treated accordingly to diagnosis with polychemotherapy. Patients affected by marginal zone and follicular lymphomas did not receive chemotherapy, undergoing instead to surgical resection; of those one patient received consolidative ipsilateral radiotherapy due to presence of positive surgical margins. No patient underwent to radical surgery or axillary dissection.

At a median follow up of 9 years (range, 0.7-17 years), four patients had relapsed, all of those were affected by high grade BL. Central nervous system (CNS) was the site of progression in two cases. Patients who presented relapse subsequently died due to malignancy. Moreover, during the follow up period one patient died due to concomitant disease. Median PFS and OS have not been reached both in the whole population (Figure $3 A, B$, respectively) and in the exploratory analysis according to primary $v s$. secondary stage (Figure $4 A, B$, respectively) and to high- $v$ s. low-grade histotype (Figure $5 A, B$, respectively). Indeed, only five patients were not censored at the time of analysis. However, a slight trend toward a better survival was noticed in favor of PBL compared with SBL (Figure $4 A, B$ ), while a clearer survival benefit was observed in the low-grade cohort (Figure $5 A, B)$. The estimated 5 -year survival rate was $77 \%$ within the whole population, $78 \%$ vs. $66 \%$ for PBL vs. SLB and $100 \%$ vs. $66 \%$ for low- vs. high-grade BL.

\section{Discussion}

$\mathrm{BL}$ is an extremely rare disease. Evidences concerning this entity rely mainly on case reports and case series rather than clinical trials and indicate that both diagnosis and management are difficult. Indeed, while clinical presentation and radiological features mimic those of 

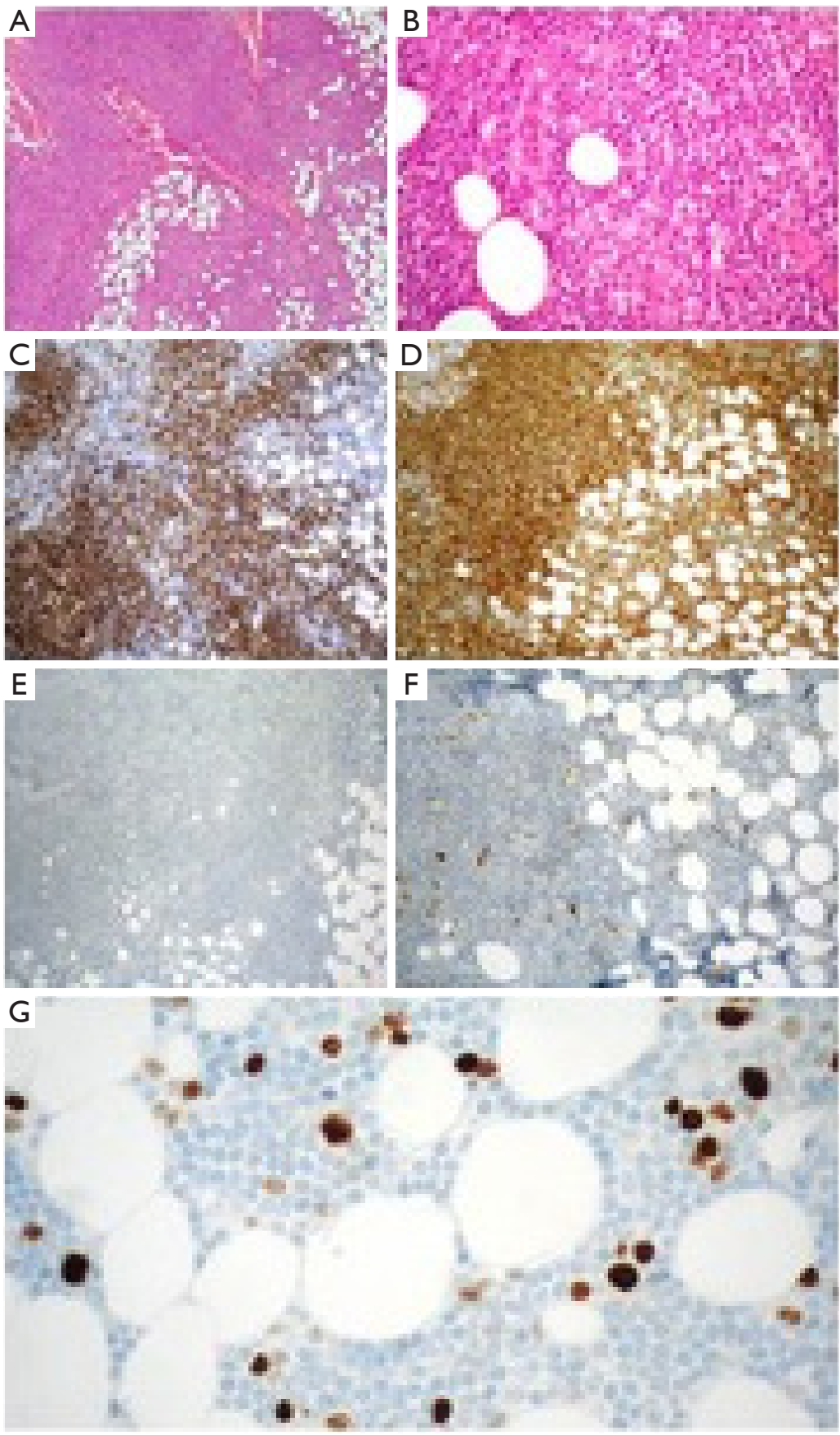

Figure 1 Marginal zone breast lymphoma: morphological and immunohistochemical findings in a low-grade lymphoma. (A) Breast parenchyma showed a diffuse infiltrate of morphologically heterogeneous small B cells (marginal zone or centrocyte-like cells, monocytoid like cells, small lymphocytes and centroblast-like cells (Haematoxylin and Eosin, $\times 4$ ); (B) the neoplastic population was composed of the characteristic marginal zone B-cells with small-medium sized nuclei with only moderately dispersed chromatin and inconspicuous nucleoli. Larger cells with a centroblastic appearance were present, but they were in the minority (Haematoxylin and Eosin, $\times 10)$. The marginal neoplastic cells showed positive immunostaining for CD20 (C, LSAB-HRP, $\times 4$ ) and Bcl2 (D, LSAB-HRP, ×4), negativity for Bcl6 (E, LSAB-HRP, $\times 4$ ) and CyclinD1 (F, LSAB-HRP, $\times 10)$. The proliferative index in the marginal component has been valued as $10 \%(\mathrm{G}, \mathrm{LSAB}-\mathrm{HRP}, \times 40)$. 

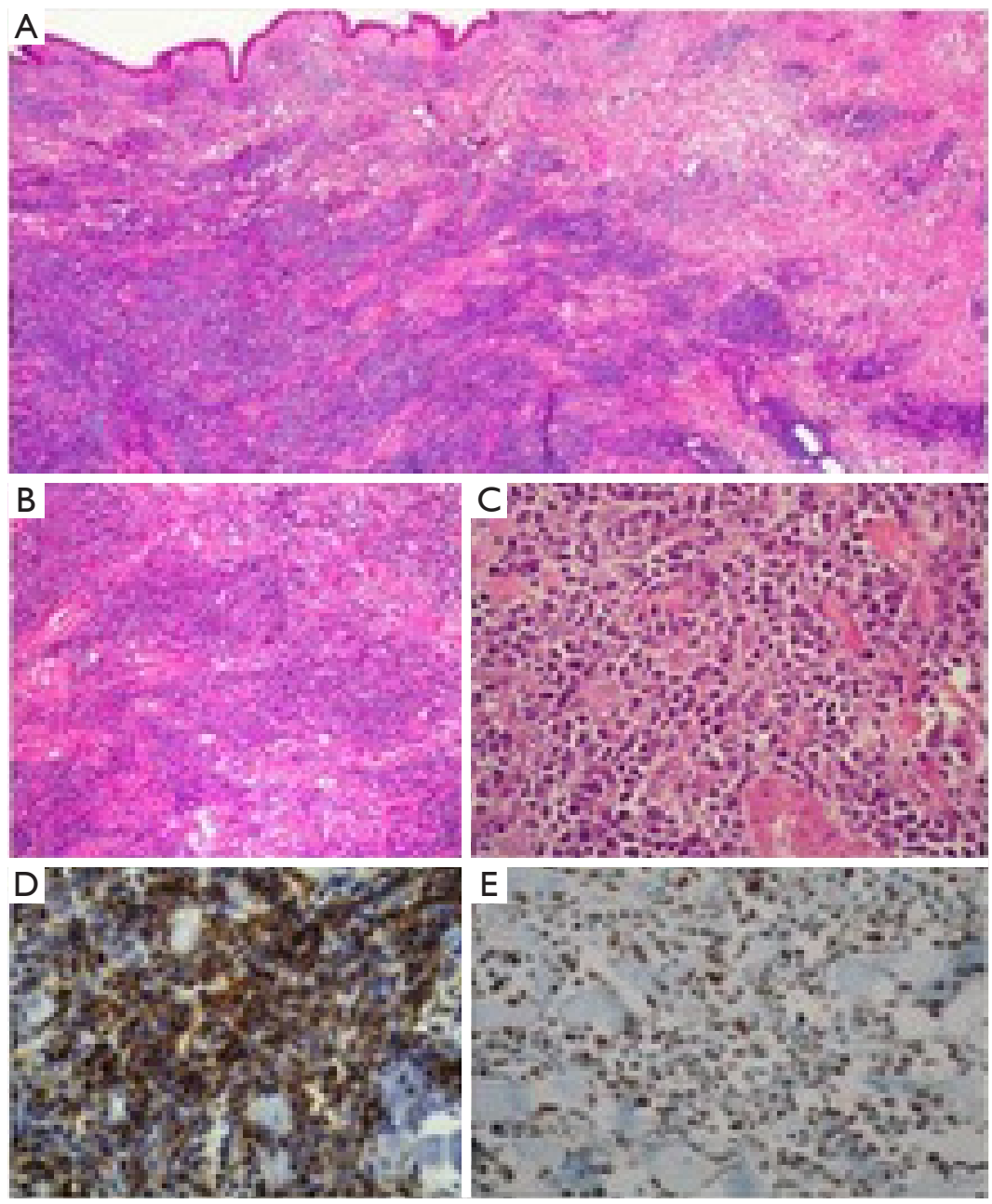

Figure 2 Diffuse B-cell lymphoma: morphological and immunohistochemical findings in a high-grade lymphoma. (A) Diffuse, massive infiltration of neoplastic large B cells in the superficial dermis with extension to the hypodermic tissue. No evidence of epidermotropism (Haematoxylin and Eosin, $\times 4$ ); (B) the lymphoid infiltrate were composed of centroblastic-like and immunoblastic-like B cells. They appeared medium-large sized with oval to round vesicular nuclei and very scant cytoplasm (Haematoxylin and Eosin, $\times 10)$; (C) a higher magnification of the neoplastic lymphoid population (Haematoxylin and Eosin, $\times 40)$; (D,E) the neoplastic cells showed positive immunostaining for CD20 (LSAB-HRP, $\times 40$ ). Note the high proliferative index (LSAB-HRP, $\times 40)$.

epithelial BC, prognosis and treatment are quite different $(13,14)$. Therefore, it should be considered in differential diagnosis in order to guarantee a correct treatment. Diagnosis relies on suspect posed by fine-needle cytology and must be confirmed by histology (18).

Here we report our single-institution experience in this specific patients' population. Demographics and clinicopathological features of our patients are in accordance with previously reported evidences. In fact, BL can develop in both gender, but occur more frequently among women $(98 \%)(5,15,20-27)$ and most cases present in the $5^{\text {th }}$ or $6^{\text {th }}$ decade of life $(3,28)$. The predominant presenting sign is a painless solitary mass (26) involving mainly the external superior quadrant of the right breast $(29,30)$, although bilateral involvement has been reported in $1-14 \%$ of cases $(31,32)$. Signs of nipple or skin involvement are infrequent $(14,15,20)$ and constitutional B symptoms (such as fever, night sweats and weight loss) are rare and usually indicative of disseminated disease $(5,21,25-27,33)$. Histologically, the majority of BL are non-Hodgkin's B-cell lymphomas and the most frequent subtype is DLBCL $(10,34)(56-84 \%)$, followed by marginal zone (9-28\%), follicular (10-19\%) 

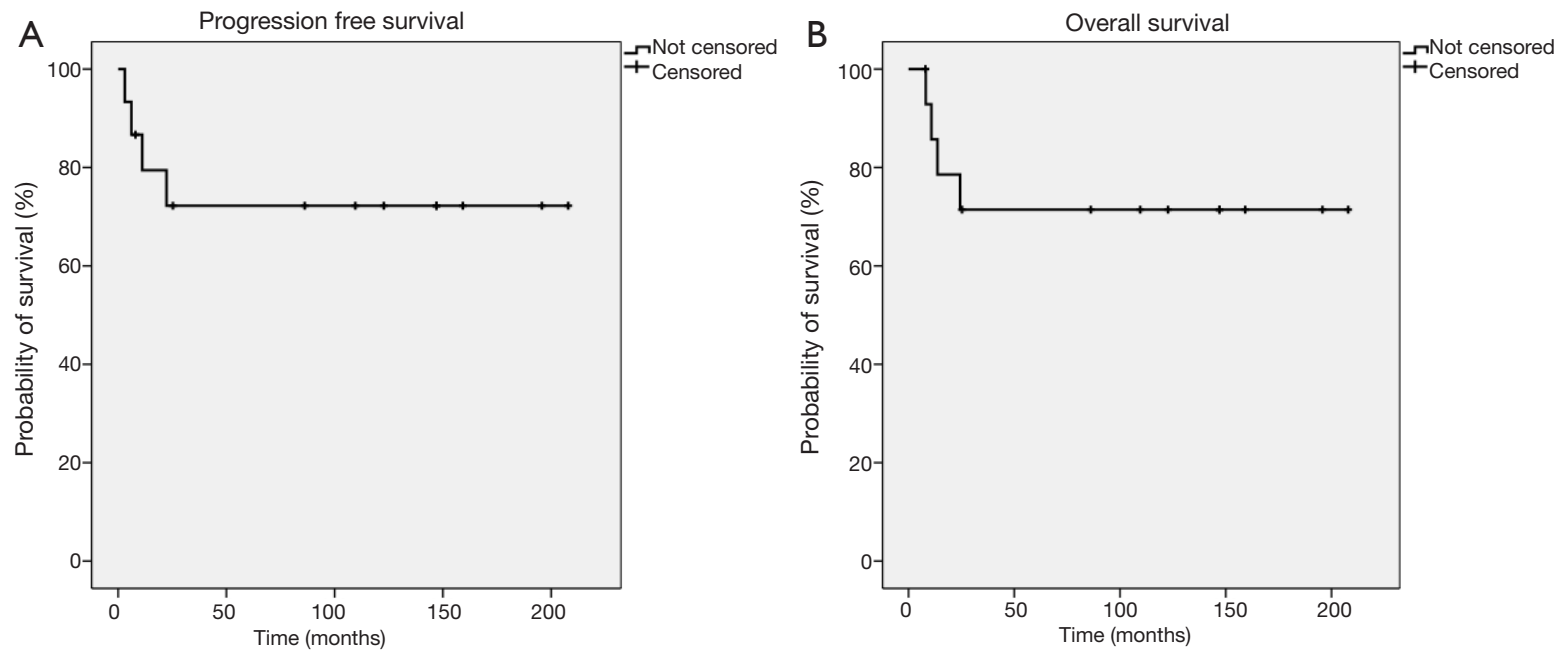

Figure 3 Survival in the whole population. (A) PFS of the whole population; (B) OS of the whole population. PFS, progression-free survival; OS, overall survival.
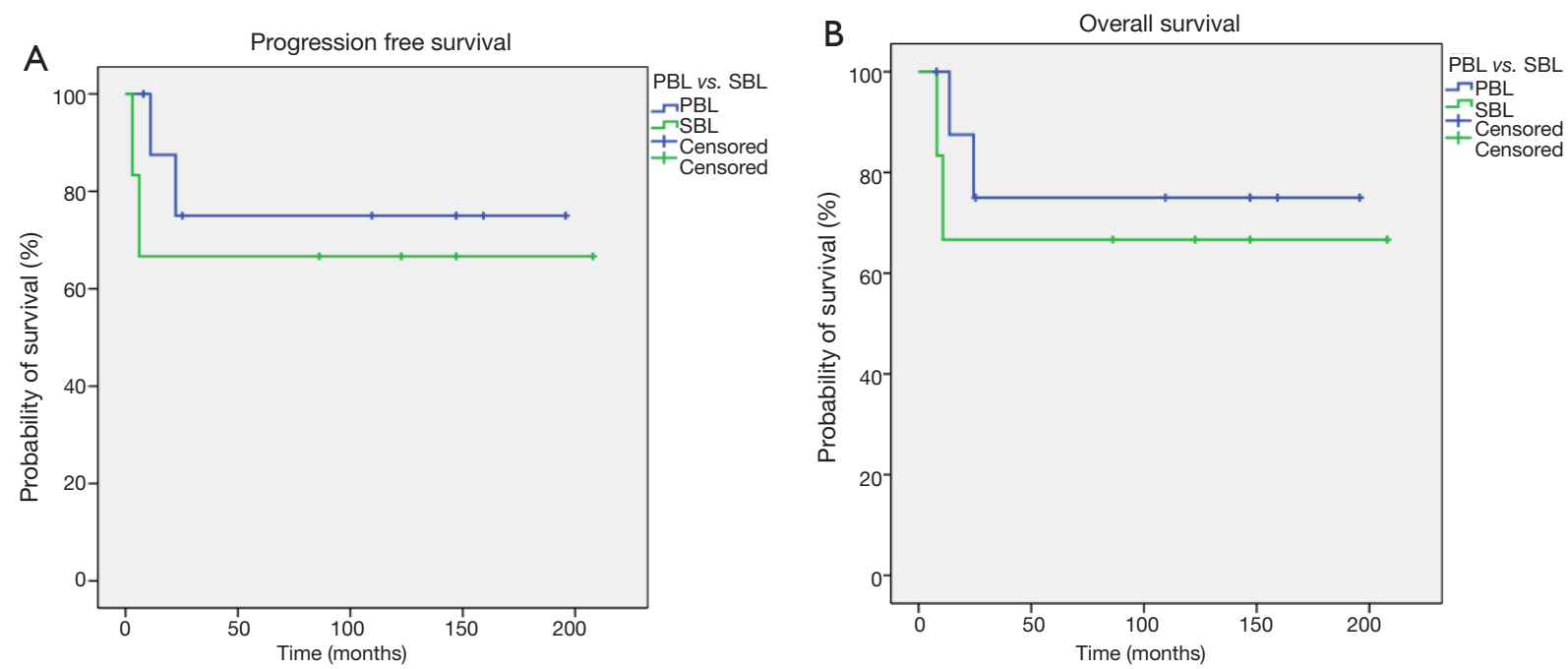

Figure 4 Survival in PBLs vs. SBLs. (A) PFS of PBLs compared with SBLs; (B) OS of PBLs compared with SBLs. PFS, progression-free survival; PBL, primary breast lymphoma; SBL, secondary breast lymphoma; OS, overall survival.

and Burkitt lymphoma (<6\%) (16).

In accordance with available data, treatment of our population was based upon histological subtype, disease staging and patients' clinical features and comorbidities. A clear difference in prognosis and management of high- and low-grade BL can be observed. Treatment strategies for high-grade BL comprise a combination of anthracyclinebased chemotherapy and rituximab followed by consolidative ipsilateral breast radiotherapy, which reduce the risk of local recurrence $(6,21,33,35)$. R-CHOP is the standard regimen for patients affected by DLBCL. Surgical interventions, preferably minimally-invasive, should be limited to biopsy to obtain the correct histological diagnosis and guide therapy. Whereas surgeries beyond excisional biopsy should be avoided since radical mastectomy and axillary dissection did not show to add any benefit in the treatment of PBL $(5,25,31,36)$, being even detrimental. Low-grade BLs do not need chemotherapy, instead should be treated with surgical excision followed by radiotherapy in case of positive margins. 

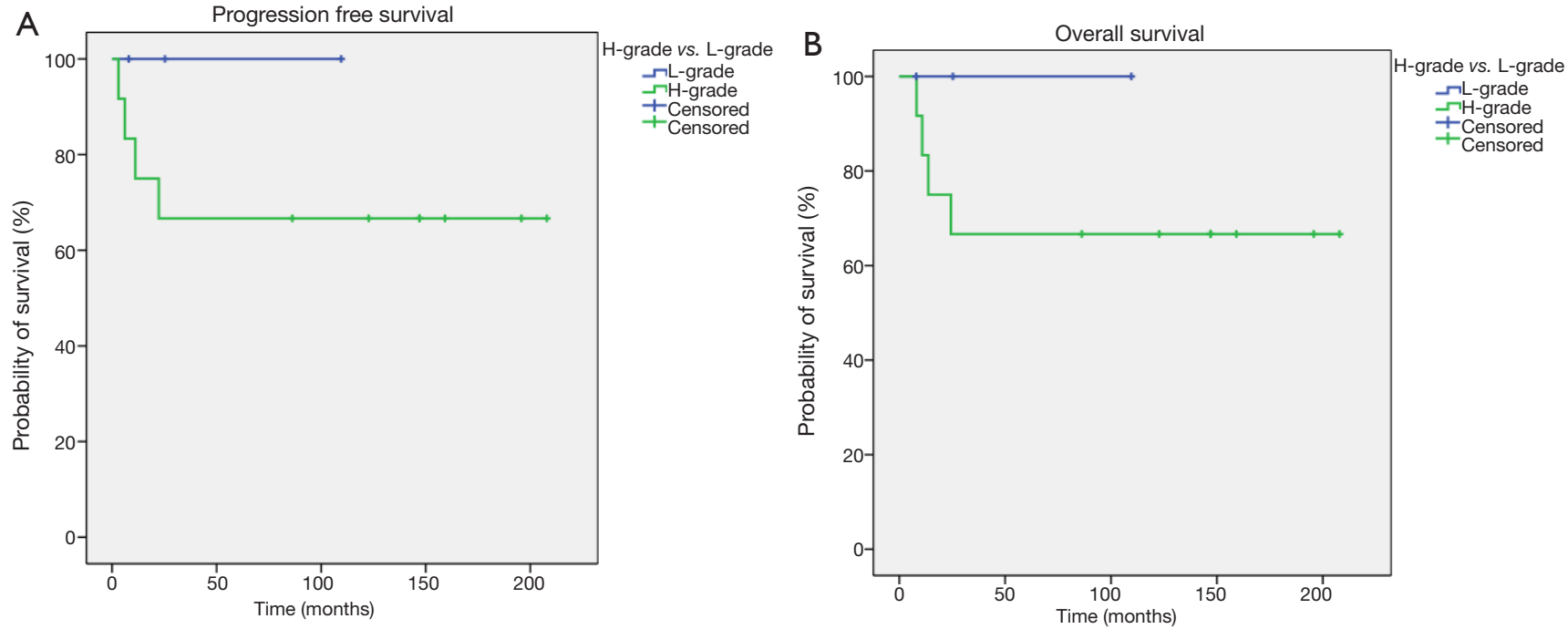

Figure 5 Survival in high-grade vs. low-grade BLs. (A) PFS of high-grade BLs compared with low-grade BLs; (B) OS of high-grade BLs compared with low-grade BLs. PFS, progression-free survival; BL, breast lymphoma; OS, overall survival.

Concerning the recurrence rate, our analysis is consistent with available data. Indeed, we reported a 5 -year survival rate of $77 \%$ in the whole population, which is in accordance with $40-80 \%$ rate previously showed (18). Moreover, relapses occurred in half cases within CNS. This is concordant with previous studies, where, despite administration of optimal treatment, extranodal progression has frequently been reported, involving mainly CNS and breast (17,37-39). Thus, given the high risk of CNS recurrence and the poor prognosis after such event, some authors hypothesized the inclusion of CNS-directed prophylaxis in the initial management of specific high-grade BLs $(21,40,41)$.

Despite median PFS and OS were not reached, a slight trend toward a better survival was noticed in favor of PBL vs. SBL and a clearer survival benefit was observed in the low-grade vs. high-grade cohort. Moreover, all patients whose disease recurred were affected by highgrade histotypes. Thus, our data corroborate the evidence that low-grade BLs display an indolent trend and allow hypothesizing that PBLs present a better prognosis compared with SBLs.

Clearly our analysis has a number of limitations. Firstly, the evaluation is limited by the selection bias connected to its retrospective nature and to the small sample size of our cohort, given the rarity of the disease. However, due to the scarcity of the disease it would be difficult to assemble a prospective analysis. Secondly, a lack of uniform approach is noted given the heterogeneous population and the long interval of observation.

Given the importance of achieving a correct histological diagnosis, it is crucial to stress the key role played by the pathologist in posing the suspect according to cytological features of fine needle aspiration and subsequently characterizing the histologic sample. In this light, it is important to note that we did not observe discrepancies between cytology suspect and histology confirmation, this is probably due to the high expertise of our dedicated breast pathologists. Moreover, multidisciplinary discussion involving clinicians, surgeons and pathologists is critical in order to define the correct treatment management, avoiding unnecessary and potentially detrimental surgeries.

\section{Conclusions}

Our results are in accordance with previously reported evidences concerning epidemiology, clinicopathological features and management of BLs. Although being a rare disease, BLs must be taken into account in differential diagnosis of breast neoplasms since treatment and prognosis are quite different. Therefore, histological characterization is crucial in order to guarantee a tailored management. Indeed, high-grade BLs should receive a combination of chemotherapy and involved-field radiation therapy, whereas low-grade BLs require loco-regional treatment only. 


\section{Acknowledgments}

Funding: None.

\section{Footnote}

Provenance and Peer Review: This article was commissioned by the editorial office, Translational Cancer Research for the series "Update of Current Evidences in Breast Cancer Multidisciplinary Management". The article has undergone external peer review.

Conflicts of Interest: All authors have completed the ICMJE uniform disclosure form (available at http://dx.doi. org/10.21037/tcr.2017.11.10). The series "Update of Current Evidences in Breast Cancer Multidisciplinary Management" was commissioned by the editorial office without any funding or sponsorship. GF served as the unpaid Guest Editor of the series and serves as an unpaid editorial board member of Translational Cancer Research from Nov 2016 to Dec 2018. $\mathrm{AMF}$ and RM served as the unpaid Guest Editors of the series. The authors have no other conflicts of interest to declare.

Ethical Statement: The authors are accountable for all aspects of the work in ensuring that questions related to the accuracy or integrity of any part of the work are appropriately investigated and resolved. The study was conducted in accordance with the Declaration of Helsinki (as revised in 2013). This is a retrospective and observational study and no approval by the Ethics Committee is required. Each patient was treated as well as in clinical practice. All patients at the time of surgery and the onset of chemotherapy have signed an informed consent, authorizing the use of their anonymized data for scientific purposes.

Open Access Statement: This is an Open Access article distributed in accordance with the Creative Commons Attribution-NonCommercial-NoDerivs 4.0 International License (CC BY-NC-ND 4.0), which permits the noncommercial replication and distribution of the article with the strict proviso that no changes or edits are made and the original work is properly cited (including links to both the formal publication through the relevant DOI and the license). See: https://creativecommons.org/licenses/by-nc-nd/4.0/.

\section{References}

1. Nicholson BT, Bhatti RM, Glassman L. Extranodal
Lymphoma of the Breast. Radiol Clin North Am 2016;54:711-26.

2. Zucca E, Roggero E, Bertoni F, et al. Primary extranodal non-hodgkin's lymphomas. part 2: Head and neck, central nervous system and other less common sites. Ann Oncol 1999;10:1023-33.

3. Bobrow LG, Richards MA, Happerfield LC, et al. Breast lymphomas: A clinicopathologic review. Hum Pathol 1993;24:274-8.

4. Jabbour G, El-Mabrok G, Al-Thani H, et al. Primary Breast Lymphoma in a Woman: A Case Report and Review of the Literature. Am J Case Rep 2016;17:97-103.

5. Ryan G, Martinelli G, Kuper-Hommel M, et al. Primary diffuse large B-cell lymphoma of the breast: prognostic factors and outcomes of a study by the International Extranodal Lymphoma Study Group. Ann Oncol 2008;19:233-41.

6. Avilés A, Delgado S, Nambo MJ, et al. Primary breast lymphoma: results of a controlled clinical trial. Oncology 2005;69:256-60.

7. Gholam D, Bibeau F, Weshi A, et al. Primary breast lymphoma. Leuk Lymphoma 2003;44:1173-8.

8. Duncan VE, Reddy VV, Jhala NC, et al. Non-hodgkin's lymphoma of the breast: A review of 18 primary and secondarycases. Ann Diagn Pathol 2006;10:144-8.

9. Tavassoli FA, Devilee P, editors. World health organization classification of tumours. Pathology \& genetics tumours of the breast and female genital organs. Lyon (France): IARC Press, 2003.

10. Domchek SM, Hecht JL, Fleming MD, et al. Lymphomas of the breast: primary and secondary involvement. Cancer 2002;94:6-13.

11. Wiseman C, Liao KT. Primary lymphoma of the breast. Cancer 1972;29:1705-12.

12. Hugh JC, Jackson FI, Hanson J, et al. Primary breast lymphoma. an immunohistologic study of 20 new cases. Cancer 1990;66:2602-11.

13. Buisman FE, van Gelder L, Menke-Pluijmers MB, et al. Non-primary breast malignancies: a single institution's experience of a diagnostic challenge with important therapeutic consequences-a retrospective study. World J Surg Oncol 2016;14:166.

14. Sabaté JM, Gomez A, Torrubia S, et al. Lymphoma of the breast: Clinical and radiologic features with pathologic correlation in 28 patients. Breast J 2002;8:294-304.

15. Yang H, Lang RG, Fu L. Primary breast lymphoma (PBL): A literature review. Clin Oncol Cancer Res 2011;8:128-32.

16. Cheah CY, Campbell BA, Seymour JF. Primary breast 
lymphoma. Cancer Treat Rev 2014;40:900-8.

17. Yhim HY, Kim JS, Kang HJ, et al. Matched-pair analysis comparing the outcomes of primary breast and nodal diffuse large B-cell lymphoma in patients treated with rituximab plus chemotherapy. Int J Cancer 2012;131:235-43.

18. Early Breast Cancer Trialists' Collaborative Group (EBCTCG), Darby S, McGale P. Effect of radiotherapy after breastconserving surgery on 10-year recurrence and 15-year breast cancer death: Meta-analysis of individual patient data for 10,801 women in 17 randomised trials. Lancet 2011;378:1707-16.

19. Swerdlow SH, Campo E, Pileri SA, et al. The 2016 revision of the World Health Organization classification of lymphoid neoplasms. Blood 2016;127:2375-90.

20. Surov A, Holzhausen HJ, Wienke A, et al. Primary and secondary breast lymphoma: prevalence, clinical signs and radiological features. Br J Radiol 2012;85:e195-205.

21. Caon J, Wai ES, Hart J, et al. Treatment and outcomes of primary breast lymphoma. Clin Breast Cancer 2012;12:412-9.

22. Jeanneret-Sozzi W, Taghian A, Epelbaum R, et al. Primary breast lymphoma: patient profile, outcome and prognostic factors. A multicentre Rare Cancer Network study. BMC Cancer 2008;8:86.

23. Talwalkar SS, Miranda RN, Valbuena JR, et al. Lymphomas involving the breast: a study of 106 cases comparing localized and disseminated neoplasms. Am J Surg Pathol 2008;32:1299-309.

24. Arber DA, Simpson JF, Weiss LM, et al. Non-Hodgkin's lymphoma involving the breast. Am J Surg Pathol 1994;18:288-95.

25. Uesato M, Miyazawa Y, Gunji Y, et al. Primary nonhodgkin's lymphoma of the breast: Report of a case with special reference to 380 cases in the Japanese literature. Breast Cancer 2005;12:154-8.

26. Validire P, Capovilla M, Asselain B, et al. Primary breast non-Hodgkin's lymphoma: A large single center study of initial characteristics, natural history, and prognostic factors. Am J Hematol 2009;84:133-9.

27. Yhim HY, Kang HJ, Choi YH, et al. Clinical outcomes and prognostic factors in patients with breast diffuse large B cell lymphoma; Consortium for Improving Survival of Lymphoma (CISL) study. BMC Cancer 2010;10:321.

28. Wong WW, Schild SE, Halyard MY, et al. Primary non-hodgkin lymphoma of the breast: The mayo clinic experience. J Surg Oncol 2002;80:19-25.

29. Inic Z, Inic M, Zegarac $M$, et al. Three cases of combined therapy in primary breast lymphoma (PBL) with successful outcomes. Clin Med Insights Oncol 2013;7:159-63.

30. Garg NK, Bagul NB, Rubin G, et al. Primary lymphoma of the breast involving both axillae with bilateral breast carcinoma. World J Surg Oncol 2008;6:52.

31. Jennings WC, Baker RS, Murray SS, et al. Primary breast lymphoma: the role of mastectomy and the importance of lymph node status. Ann Surg 2007;245:784-9.

32. Meroni S, Moscovici OC, Rahal D, et al. Synchronous bilateral primary breast lymphoma. Breast J 2012;18:378-9.

33. Hosein PJ, Maragulia JC, Salzberg MP, et al. A multicentre study of primary breast diffuse large B-cell lymphoma in the rituximab era. Br J Haematol 2014;165:358-63.

34. Cox J, Lunt L, McLean L. Haematological cancers in the breast and axilla: a drop in an ocean of breast malignancy. Breast 2005;14:51-6.

35. Avilés A, Castañeda C, Neri N, et al. Rituximab and dose dense chemotherapy in primary breast lymphoma. Haematologica 2007;92:1147-8.

36. Ganjoo K, Advani R, Mariappan MR, et al. Non-Hodgkin lymphoma of the breast. Cancer 2007;110:25-30.

37. Barişta I, Baltali E, Tekuzman G, et al. Primary breast lymphoma - a retrospective analysis of twelve cases. Acta Oncol 2000;39:135-9.

38. Ribrag V, Bibeau F, Weshi A, et al. Primary breast lymphoma: a report of 20 cases. Br J Haematol 2001;115:253-6.

39. DeBlasio D, McCormick B, Straus D, et al. Definitive irradiation for localized non-Hodgkin's lymphoma of breast. Int J Radiat Oncol Biol Phys 1989;17:843-6.

40. Arkenau HT, Chong G, Cunningham D, et al. The role of intrathecal chemotherapy prophylaxis in patients with diffuse large B-cell lymphoma. Ann Oncol 2007;18:541-5.

41. Boehme V, Zeynalova S, Kloess M, et al. Incidence and risk factors of central nervous system recurrence in aggressive lymphoma - a survey of 1693 patients treated in protocols of the German High-Grade Non-Hodgkin's Lymphoma Study Group (DSHNHL). Ann Oncol 2007;18:149-57.

Cite this article as: Orlandi A, Sanchez AM, Calegari MA, D'Archi S, Santoro A, Di Leone A, Mulè A, Arena V, Masetti R, Barone C, Franceschini G. Diagnosis and management of breast lymphoma: a single-institution retrospective analysis. Transl Cancer Res 2018;7(Suppl 3):S272-S280. doi: 10.21037/ tcr.2017.11.10 